\title{
ENDOCRINE CONTROL OF THE OESTROUS CYCLE
}

\author{
G.R. FOXCROFT
}

Physiology and Environmental Studies, University of Nottingham School of Agriculture, Sutton Bonington, Loughborough, UK

D.F.M. VAN DE WIEL

Research Institute for Animal Husbandry "Schoonoord", Driebergseweg 10 $D$, Zeist, The Netherlands

The study of the mechanisms controlling the oestrous cycle of the sow has already illustrated some important comparative differences from other species, although even the direct measurement of those circulating hormones involved in controlling ovarian activity is still incomplete. While some technical difficulties exist in using the pig for in vivo experimentation, the relatively high levels of circulating ovarian steroids make it an excellent animal in which to study steroid-gonadotrophin interactions. Furthermore the ready availability of porcine ovarian tissue has resulted in the accumulation of a considerable body of evidence from in vitro experimentation related to the intra-ovarian mechanisms involved in the integrated control of the hypothalamic-pituitary-ovarian axis.

The major objective of this Chapter is to establish a possible model for the control of the oestrous cycle in the pig with reference to pertinent data from both in vivo and in vitro studies. To some extent this precludes an exhaustive coverage of the available literature, but where possible, reference is made to papers in which more detailed information is available. In attempting to achieve these objectives the oestrous cycle will be divided into five phases which will be considered in a chronological sequence as follows:

(a) the established luteal phase of the cycle;

(b) luteal regression;

(c) the early follicular phase;

(d) the late follicular phase and the pre-ovulatory surge of gonadotrophins;

(e) the periovulatory period (including the early luteal phase)

\section{The established luteal phase of the cycle}

Several aspects of hypothalamo-hypophysial-ovarian function peculiar to those mammals that exhibit long luteal phase cycles have been discussed in the general context of cyclic control by Greenwald (1979). As the maintenance of luteal function appears to dictate the length of the cycle, 

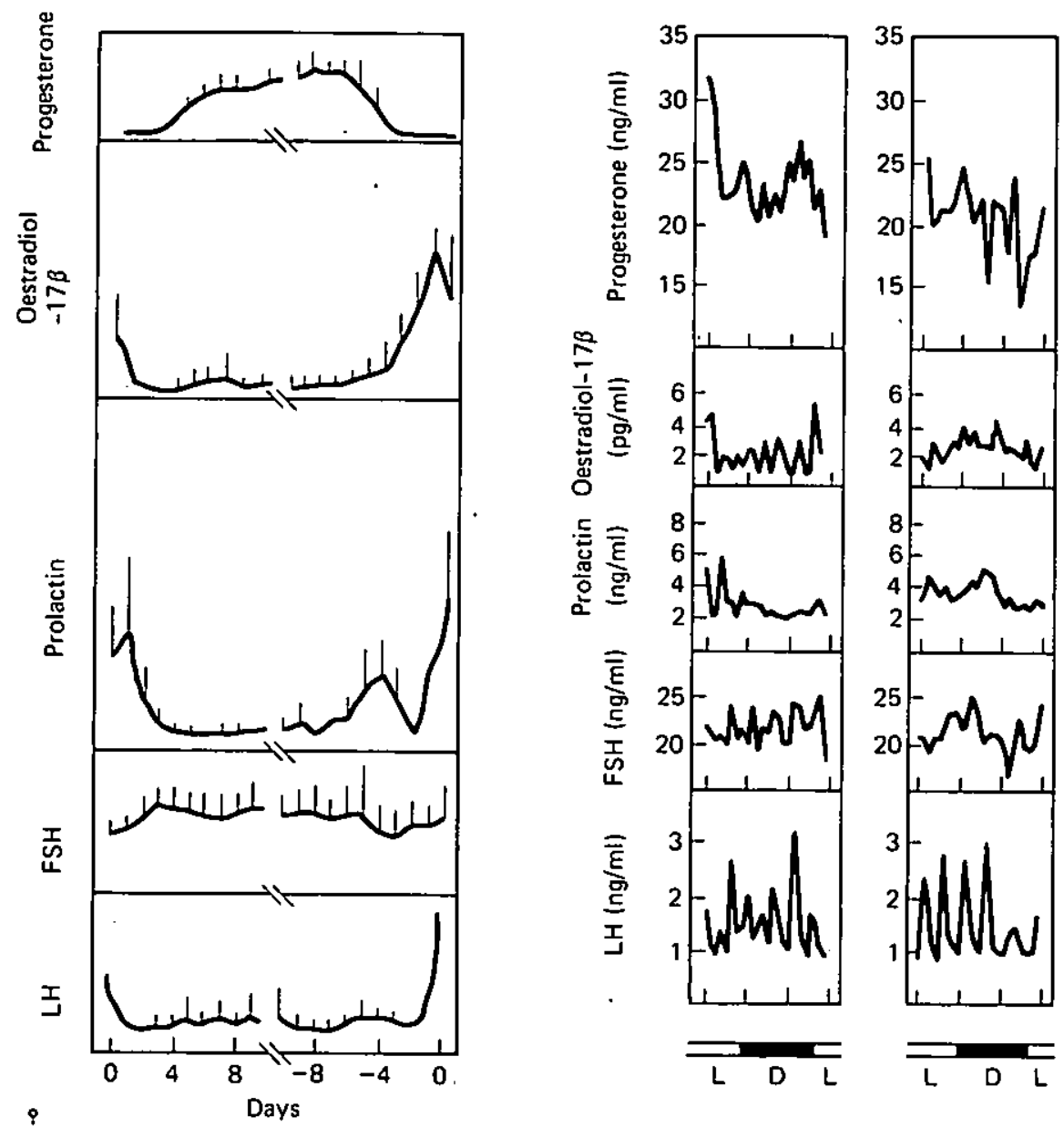

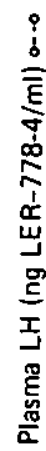
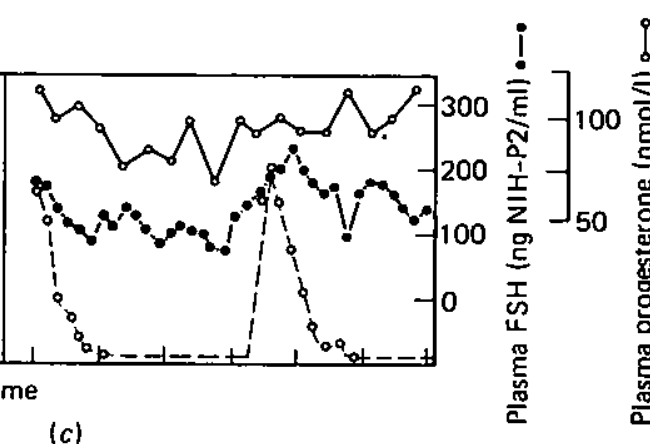

Figure 8.1 (a) Mean relative changes in circulating hormones (+SDM) throughout the oestrous cycle of the pig (day $0=$ day of LH surge), as determined by daily sampling. (b) Changes in circulating hormones on days 11-12 of the oestrous cycle in two intact pigs sampled at hourly intervals for 24 hours. $\mathrm{L}=$ light, $\mathrm{D}=$ dark periods. (c) Changes in circulating $\mathrm{LH}(\mathrm{O}-\mathrm{O})$, FSH $\left(\mathrm{O}_{-}\right)$and progesterone $(\mathrm{O}-\mathrm{O})$ during the mid-luteal phase of the oestrous cycle in two pigs sampled at 10 minute intervals for 6 hours. (a) and (b) after Van de Wiel et al. (1981); (c) Foxcroft and Edwards, unpublished observations 
the choice of the 'established' luteal phase as a starting point for a consideration of cyclic control seems logical.

The changes in peripheral progesterone concentrations are the best documented endocrine events of the pig oestrous cycle (Tillson and Erb, 1967; Stabenfeldt et al., 1969; Tillson, Erb and Niswender, 1970; Edquist and Lamm, 1971; Shearer et al., 1972; Henricks, Guthrie and Handlin, 1972; Parvizi et al., 1976; Van de Wiel et al., 1981), although some inconsistencies still exist in these data. As shown in Figure 8.1(a), a rise in progesterone secretion is generally observed on days 3-4 of the oestrous cycle (the first day of standing heat being designated as day 0 ), but considerable variability exists as to the time of maximum circulating concentrations. Some data suggest that peripheral levels may begin to decline as early as day 10 of the cycle as opposed to day 15 in other work; variations in sampling frequency may explain some of these differences but Perotti et al. (1979) have also observed differences in the pattern of progesterone secretion that appear to be related to season.

As it is important to obtain a clearer indication of the timing of the changes in progesterone production in developing a model for the onset of luteolysis, estimates of progesterone secretion based on ovarian vein sampling are of particular interest. Gomes, Herschler and Erb (1965) reported that the ovarian vein concentration of progesterone was maximal on days $10-12$, declined slowly to days $13-15$ and then fell rapidly. These findings are consistent with the report of Masuda et al. (1967) that the production rate (involving measurements of both ovarian vein concentration and blood flow) of progesterone was maximal on day 8 , declined slowly to day 12 and then again fell more rapdidly.

These data suggest that a decline in progesterone secretion as early as day 10 should be reflected in an earlier decline in progesterone in the peripheral circulation than is frequently observed. However, recent data (Hillbrand, F.W. and Elsaesser, F., personal communication) demonstrate that a very substantial amount of progesterone (up to 100 times that in the circulation) may be sequestered in the body fat of the sow. Following a fall in ovarian progesterone output the return of this fat 'depot' into the circulation will result in a latent fall in circulating progesterone levels. These observations have important implications for the control of the cycle as the initial decrease in progesterone secretion by the corpora lutea (the onset of luteolysis?) may occur as early as day 10 of the cycle, and yet any withdrawal of an effect of progesterone acting at the hypothalamicpituitary level will be seen considerably later.

The necessity for luteotrophic support during the oestrous cycle has been the subject of considerable debate and much of the early evidence (Nalbandov, 1970; Hansel, Concannon and Lukaszewska, 1973) suggested that once the signal for luteinization has occurred in the form of the pre-ovulatory surge of luteinizing hormone (LH), the corpora lutea are essentially autonomous for the duration of the luteal phase of the cycle. Thus, neither hypophysectomy early in the cycle (du Mesnil du Buisson and Leglise, 1963) nor treatment with LH antisera (Spies, Slyter and Quadri, 1967) appear to affect luteal function.

Nevertheless a number of more recent observations suggest that the corpora lutea of the cycle may be responsive to luteotrophic stimuli. 
Watson and Leask (1975) used an in vitro superfusion system to study the steroidogenic activity of porcine luteal tissue obtained during the cycle and reported an increase in progesterone secretion in response to both pulses and infusions of LH. Furthermore, an increase in oestrogen was also observed, suggesting that in agreement with the results of Weiss, Brinkley and Young (1976), the corpora lutea may also secrete oestrogens during the luteal phase of the cycle. From their study of LH-progesterone interactions during the oestrous cycle of the miniature pig Parvizi et al. (1976) also suggested that episodes of LH tended to precede and be associated with, elevations in peripheral progesterone, although no such relationship was clearly established in the domestic sow in the data of Van de Wiel et al. (1981), nor in unpublished observations at Nottingham University (see Figure 8.1(c)). However, during the mid-luteal phase Van de Wiel et al. (1981) did suggest a possible relationship between LH episodes and oestradiol secretion (see Figure 8.1(b)). Thus, although a distinct pattern of high amplitude, low frequency LH episodes has been reported by a number of authors during the luteal phase of the cycle (Rayford, Brinkley and Young, 1971; Parvizi et al., 1976; Foxcroft, 1978; Van de Wiel et al., 1981), as shown in Figure 8.1, conclusive evidence is still needed for a physiological role for $\mathrm{LH}$ at this time. Specific luteal binding of both prolactin and LH have been reported (Rolland, Gunsalus and Hammond, 1976; Ziecik, Shaw and Flint, 1980) again suggesting that such hormones may be involved in controlling luteal activity.

\section{Luteal regression}

As in other species prostaglandin $F_{2 \alpha}$ (PGF) has been postulated to be the major signal for luteolysis in the pig and the evidence to support this hypothesis is extensively reviewed by Bazer (Chapter 12). In contrast to other species, exogenous PGF will not cause luteolysis before day 12 in the pig, suggesting that the PGF-sensitive mechanism is inoperative in the early stages of the cycle. The means by which PGF of uterine origin is transferred to the ovarian artery has also been extensively investigated and in addition to an accepted vascular route of transfer, Kotwica (1980) has recently reported a possible involvement of the lymphatic circulation.

The mechanism of action of prostaglandins in the pig is unresolved. Exogenous gonadotrophin is ineffective in maintaining the corpora lutea of the cycle in the presence of an intact uterus (Anderson, 1966), suggesting that PGF inactivates some component of the LH stimulatory mechanism that is effective in maintaining luteal function in hysterectomized females. A dramatic decrease in unoccupied LH receptors was observed by Ziecik, Shaw and Flint (1980) after day 12 of the cycle and an increase in an LH receptor binding inhibitor of luteal origin has been associated with increasing age of the corpus luteum (Tucker, Kumari and Channing, 1979). These data would therefore be consistent with the theory that at the time of luteal regression the corpora lutea may be LH-dependent and that loss of the LH receptor mechanism within luteal tissue results in the decline in progesterone synthesis that occurs as early as day 12 of the cycle. In addition there is evidence that the initial luteolytic stimulus from the uterus may also activate the local production of PGF within the corpus luteum 
itself, thus reinforcing the luteolytic effect of prostaglandins (Guthrie, Rexroad and Bolt, 1979).

Two other phenomena exist in the late luteal phase of the cycle of the sow that contrast with the situation in other large domestic species. The first is the ability of exogenous oestrogen to block the luteolytic effects of prostaglandin and considerably extend luteal function (see Bazer, Chapter 12). The mechanism by which oestrogen exerts this luteotrophic effect may involve the redirection of prostaglandin as is proposed for the early stages of pregnancy, but preliminary evidence discussed during this meeting (Garverick, Flint and Polge, unpublished observations) indicates that oestrogen may also act to increase LH receptors in the corpora lutea. Although the luteotrophic effect of oestrogen appears to have little physiological significance for the control of the normal cycle, these data again suggest that the presence of adequate $\mathrm{LH}$ receptors may be critical to continued luteal function at the end of the cycle. Secondly, there are consistent reports of markedly elevated levels of prolactin at the time of luteal regression (Wilfinger, 1974; Van Landeghem and Van de Wiel, 1977; Van de Wiel et al., 1981). The close relationship between this rise in prolactin and the decline in peripheral progesterone concentrations invites speculation concerning a luteolytic role for prolactin and Rolland, Gunsalus and Hammond (1976) have suggested that evidence exists for an inhibitory effect of prolactin on progesterone secretion, at least in porcine granulosa cells. However, Van de Wiel et al. (1981) also emphasize the close relationship between the same prolactin rise and the initial increase in oestradiol secretion and therefore a possible role in the stimulation of follicular growth and steroidogenesis as discussed in the next section.

\section{The early follicular phase}

Although the adopted sequence in this review suggests that the follicular phase of the cycle can be discretely separated from the luteal phase of the cycle, this may be misleading. The data currently available indicate that important changes occur as a continuum in developing follicles between the time of antral formation and the time that they achieve a size of $6-12 \mathrm{~mm}$ and become pre-ovulatory Graafian follicles at the end of the oestrous cycle. Thus, the number of granulosa $\mathrm{LH}$ receptors increase approximately 100 -fold, $\mathrm{LH}$-stimulated increases in cyclic AMP increase in magnitude, the sensitivity of the cyclic AMP response to prostaglandin E decreases, the ability of the granulosa to secrete progesterone and to convert androgen to oestrogen increases and the ability of follicle stimulating hormone ( $\mathrm{FSH})$ to stimulate the aromatization of androgen in the granulosa only becomes apparent in large follicles (Anderson, Schaerf and Channing, 1979; Leung, Tsang and Armstrong, 1979; Schwartz-Kripner and Channing, 1979). Taken together these observations suggest that the control of follicular growth and steroidogenesis in the pig may follow a similar pattern to that proposed for the rat (Armstrong and Dorrington, 1977; Richards, Rao and Ireland, 1978) in which the initiation of responses by the follicle involve an LH-induced increase in androgen production by the thecal tissue followed by an increase in the aromatization of this androgen to oestrogen by the granulosa cells. Such changes are mediated 
(1w/t-8LL - 8эา 6u) Hา

(|w/6d) d $\angle 1-10$ !pensso

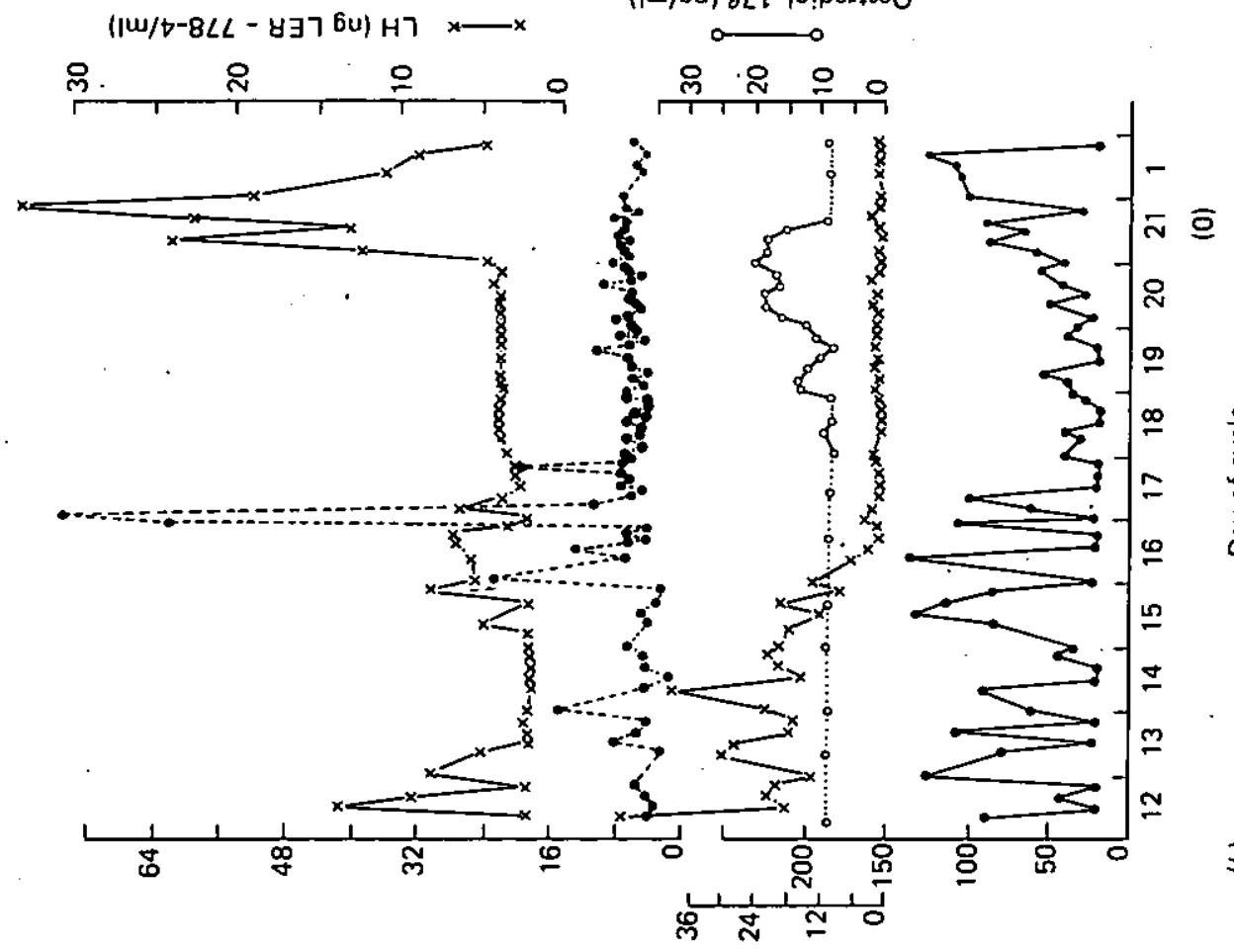

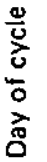

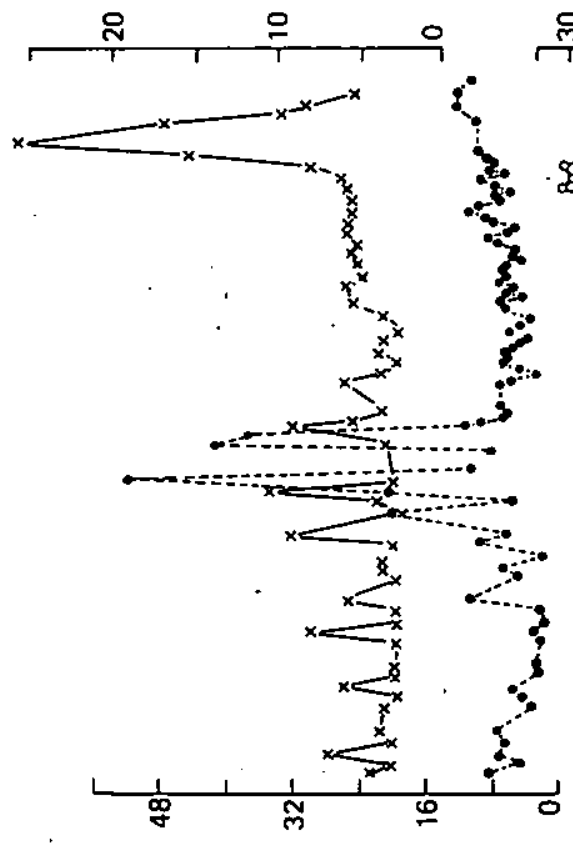

$\bullet--(\mid \omega / 6 u)$ u!joejosd

윰유, 웅ㅇ
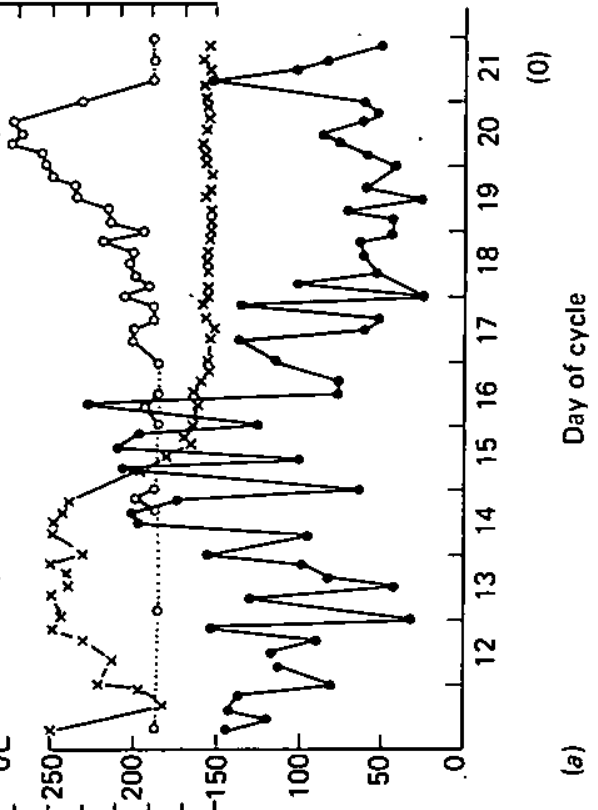
by oestrogen-dependent changes in receptors for both LH and FSH in the granulosa and through the induction of the aromatase enzymes at an intracellular level.

In view of the timing of many of these initial changes in the follicle it is difficult to determine those changes in gonadotrophin secretion, if any, that act as the stimuli for the onset of follicular development. As discussed later, some evidence suggests that the pre-ovulatory gonadotrophin surge of the previous cycle may be responsible for the recruitment of a new crop of follicles and, in the absence of any further specific gonadotrophin signal, ordered sequences of maturational changes may occur that are entirely dependent on intra-ovarian control mechanisms. However, as is well known, such changes only result in limited growth of the follicles and the absence of a major increase in oestradiol production, if progesterone levels are maintained beyond day 14-17 of the cycle. This suggests that high levels of progesterone block further maturation of the follicle and it would be of considerable interest to know whether this is a direct, or indirect, effect. Initial observations (Foxcroft, 1978) demonstrate that, as in other species, the decline in progesterone secretion leads to a gradual increase in the frequency, and a decrease in the amplitude, of LH episodes as well as a gradual decline in circulating FSH levels. However as discussed on p. 165 (Henricks, Guthrie and Handlin, 1972; Van de Wiel et al., 1981), the initial fall in progesterone is also concurrent with both the initial rise in peripheral oestradiol and an increase in prolactin secretion and it is not possible to determine cause or effect from these data.

In the sow, therefore, although important intra-ovarian changes have been described that are undoubtedly associated with normal follicular development during the cycle, the trigger for the onset of increased oestrogen secretion in the late luteal/early follicular phase of the cycle is unknown. If the decline in progesterone is related to the appearance of a trigger of pituitary origin, then this can only be associated with a qualitative change in the pattern of $\mathrm{LH} / \mathrm{FSH}$ secretion rather than a simple quantitative increase in gonadotrophin release. The possibility exists however that progesterone may exert its block to follicular development entirely at the ovarian level and that the changing patterns of $\mathrm{LH} / \mathrm{FSH}$ secretion are merely indirect consequences of the changes in circulating steroids and have no physiological significance as ovarian stimuli other than in maintaining a minimum level of gonadotrophin in the circulation. In discussing such indirect effects of progesterone it is relevant to note that in the luteal phase of the cycle no positive feedback response to oestrogen can be elicited (Foxcroft and Edwards, unpublished data); thus even in the presence of oestrogen secretion a central block to ovulation exists. The overall changes in circulating hormones at the time of luteal regression are shown in Figure 8.2 to give an indication of the complexity of the relationships that exist at this time. Further detailed studies relating such changes to intra-ovarian developments at this critical stage of the cycle are clearly required.

\section{The late follicular phase and the pre-ovulatory surge of gonadotrophins}

The net effect of the changes described in the previous section is a major rise in circulating oestrogen between days 18 and 20 of the cycle. This 

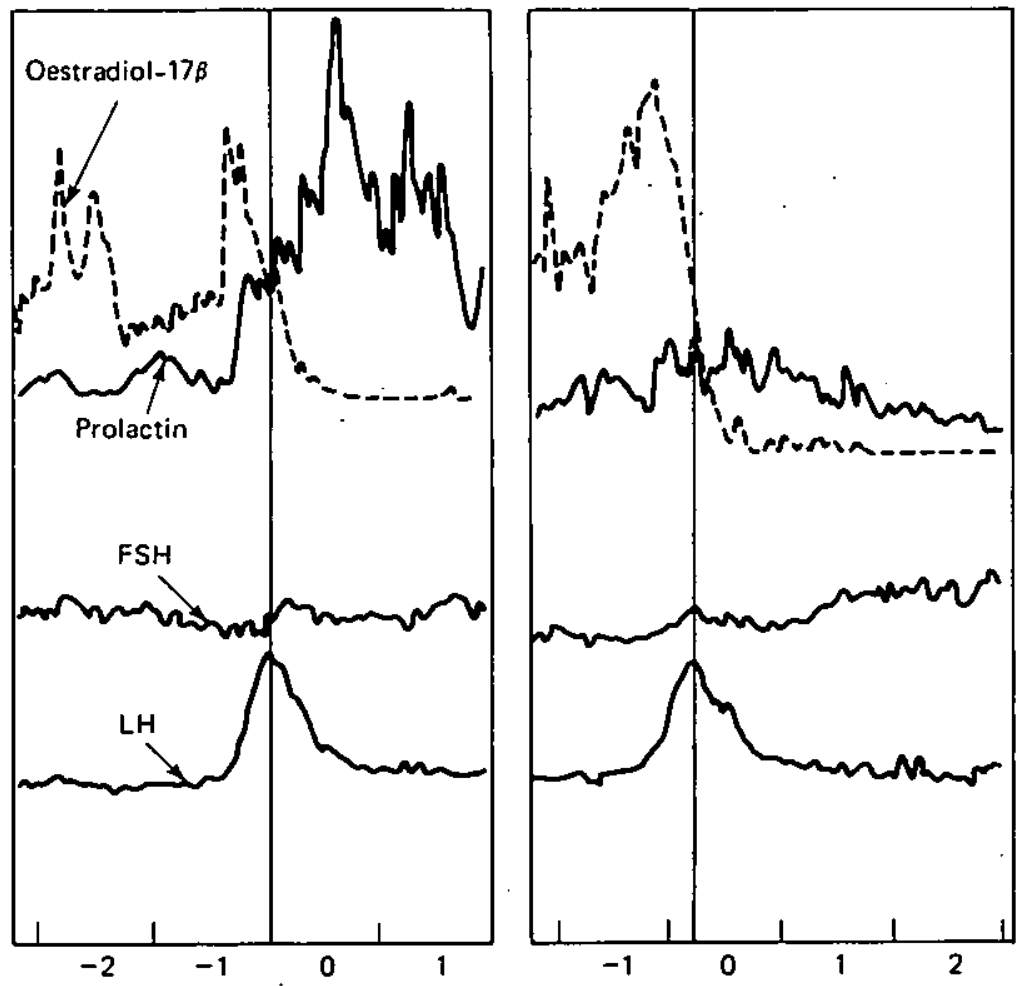

Day of cycle

Figure 8.3 Relative changes in plasma levels of circulating hormones in the late follicular phase of the oestrous cycle in two intact pigs sampled at hourly intervals. Day $0=$ first day of oestrous; vertical line $=$ time of maximum LH levels. From Van de. Wiel et al. (1981)

pattern of oestrogen release was initially determined indirectly by the measurement of urinary oestrone clearance (Lunaas, 1962; Raeside, 1963; Liptrap and Raeside, 1966) and subsequently confirmed by the direct estimation of oestradiol-17 $\beta$ in peripheral plasma by radioimmunoassay (Henricks, Guthrie and Handlin, 1972; Shearer et al., 1972; Van de Wiel $e t$ al. , 1981). The temporal relationship between this rise in oestrogen and the pre-ovulatory surge of LH and FSH (shown in Figure 8.3) suggested that as in other species the rise in oestrogen triggered a positive feedback mechanism within the hypothalamus. Confirmation that oestrogen could exert this effect in the mature domestic sow has come from the studies of Edwards (1980) and the latency of the response appears to be approximately 50-55 hours in this species. The increase in circulating oestradiol results initially in complete and immediate suppression of episodic LH release, whilst its precise effect on the basal levels of $\mathrm{LH}$ needs clarification (Foxcroft, 1978). In contrast the inhibitory effect on FSH is much more latent, although FSH levels typically reach minimal levels within individual animals immediately preceding the pre-ovulatory surge of gonadotrophins (Vandalem et al., 1979; Van de Wiel et al., 1981). A detailed assessment of FSH levels during the late follicular phase demonstrates, however, that 
there are periods of active FSH secretion in the presence of high concentrations of oestradiol, at a time when marked suppression of $\mathrm{LH}$ release exists (see Figures 8.2 and 8.3 ). This differential feedback effect on LH/FSH release seems to merit further study and as this pattern of gonadotrophin secretion provides a considerable contrast to that in other large domestic species with a low litter size, it may be of considerable comparative significance.

As shown by Van de Wiel et al. (1981) in the cyclic gilt and by Edwards (1980) in the weaned domestic sow, the initial rise in pre-ovulatory LH precedes the rapid decline in oestradiol secretion, resulting in the occurrence of peak levels of oestradiol in the circulation approximately 8-15 hours before peak LH levels are observed (see Figure 8.3). The characteristics of the pre-ovulatory LH surge at the time of oestrus were initially determined by bioassay and in retrospect the observation of Liptrap and Raeside (1966) that a rise in plasma LH occurred some $40-48$ hours before ovulation suggests that the ovarian cholesterol depletion assay used by these authors provided a reliable estimate of LH changes. The first data obtained by radioimmunoassay were those of Niswender, Reichert and Zimmerman (1970) who reported an LH surge with a duration of approximately 20 hours coincident with the onset of oestrus. These data have been confirmed in subsequent studies of cyclic gilts and sows (Henricks, Guthrie and Handlin, 1972; Rayford, Brinkley and Young, 1971; Parvizi et al., 1976; Vandalem et al., 1979; Van de Wiel et al., 1981) and in the weaned sow (Edwards, 1980).

Two points are perhaps worthy of comment with respect to the LH surge. Firstly, on the basis of published data, the precise relationship between the onset of behavioural oestrus and the time of the LH surge appears to be variable and these events may be displaced by as much as 12 hours in either direction (Foxcroft, Tilton, Ziecik and Coombs, unpublished data). Therefore, assuming a fixed interval between the LH surge and ovulation (36-40 hours), the possibility exists that the time of ovulation within the heat period may vary considerably and this may be of consequence if the number of matings per sow is restricted and related entirely to the onset of heat.

Secondly, a comparison of maximum LH levels associated with tonic episodic secretion during the luteal phase of the cycle (approximately $3 \mathrm{ng} / \mathrm{ml}$ ) and the maximum levels observed during the LH surge of $6 \mathrm{ng} / \mathrm{ml}$ (Van de Wiel et al., 1981) demonstrates that compared with other species the LH surge of the pig is characterized by a relatively moderate percentage increase in $\mathrm{LH}$, but that this elevation is of considerable duration.Again in comparative terms it will be very interesting to determine whether this pattern of $\mathrm{LH}$ secretion is of physiological significance.

Compared with the pre-ovulatory LH surge, the FSH response to oestradiol positive feedback is variable and Van de Wiel et al. (1981) suggest that it might be explained solely on the basis of the withdrawal of the inhibitory effect of oestrogens at this time. However, consideration of the data of other authors (Rayford et al., 1974; Vandalem et al., 1979) suggests that an FSH 'surge' is generally a consistent event and is frequently followed by a temporary fall in FSH levels prior to a subsequent rise as discussed on p. 171. Furthermore in studies of both gilts (Elsaesser 
and Foxcroft, 1978) and sows (Edwards, 1980) in which a pre-ovulatory gonadotrophin surge was induced by exogenous oestrogen, an FSH rise occurred at a time when oestradiol levels were still elevated and able to block the rise in FSH observed subsequently in control animals (see Figure 8.4). These data are considered to provide conclusive evidence for a direct oestrogen-induced surge of FSH release coincident with the LH surge, though of reduced magnitude.

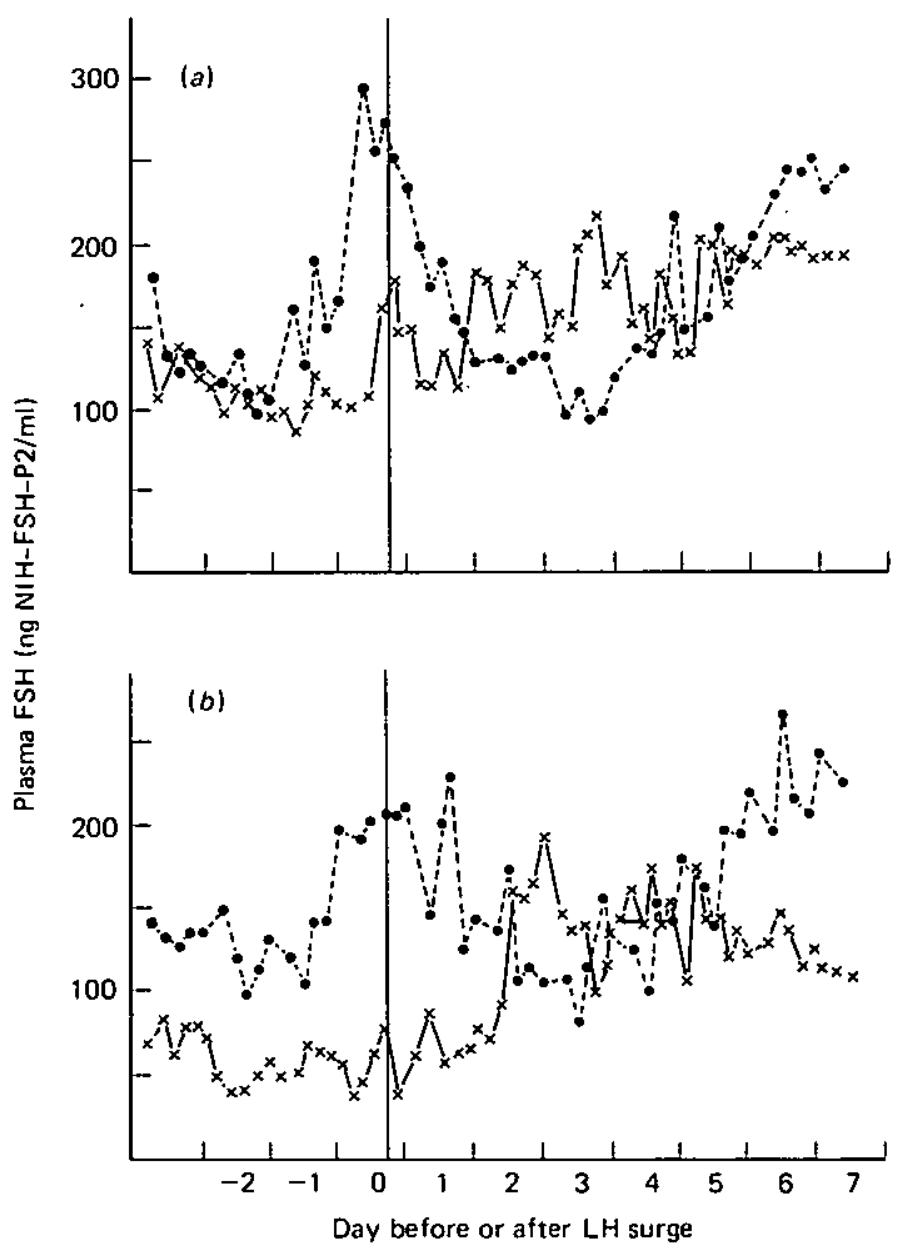

Figure 8.4 Mean plasma levels of FSH measured at 4-hourly intervals in groups of multiparous sows following weaning. Data are standardized to the time that maximal LH levels were observed in the same animals (shown by vertical line on day 0 ). Standard errors are omitted for clarity of presentation. (a) Sows weaned after a 5-week laciation and (b) after a 3-wcek lactation. Continuous lines represent data from sows returning to oestrus naturally; broken lines represent data from sows treated with $30 \mu \mathrm{g} / \mathrm{kg}$ oestradiol benzoate $(O B) \mathrm{i} . \mathrm{m}$. on the second day after weaning. Following 3-week weaning (b), a pre-ovulatory surge of FSH was observed in only $1 / 6(\mathrm{OB}$ treated) and $0 / 6$ (untreated) sows compared with $8 / 12$ (untreated) and 5/6 (OB treated) sows weaned at 5 weeks. OB treatment consistently suppressed a rise in FSH'seen in the periovulatory period (day+1 to day+4) in untreated sows. From Edwards (1981) 
Some of the immediate consequences of the rise in LH within the ovary have been well documented from in vitro studies of granulosa tissue from the pig and other species (see reviews of Hunzicker-Dunn, Bockaert and Birnbaumer, 1978; Hunzicker-Dunn et al., 1979; Catt et al., 1979), and result in the luteinization of the theca and granulosa tissue, a rapid decline in oestradiol production followed by a gradual increase in progesterone synthesis and ultimately in ovulation.

The surge of LH itself is also thought to directly act by overriding an inhibition of oocyte maturation exerted by a non-steroidal Oocyte Maturation Inhibitor (OMI) found in follicular fluid (Channing, 1979) which is present at higher concentrations in small as compared with large follicles (Van de Wiel et al., 1982). In addition the surge may also result in an efflux of follicular fluid steroids that accumulate at almost pharmacological levels within the developing follicle and may also act as important intra-ovarian regulators (Eiler and Nalbandov, 1977).

An absolute requirement for a concomitant rise in FSH in stimulating such changes appears to be questionable in the pig, as a normal sequence of periovulatory events is observed in early weaned sows in which an FSH 'surge' is frequently absent (Edwards, 1980; see Figure 8.4).

\section{The periovulatory period}

Although dependent on the exact relationship between the onset of oestrus and the time of the LH surge (see above), ovulation generally occurs during the latter part of day 2 of the oestrous cycle. At this time LH levels in both cyclic gilts and weaned sows are consistently low, in contrast to a marked increase in the release of FSH during days 2-3 of the cycle (Rayford et al., 1974; Vandalem et al., 1979; Edwards, 1980; Van de Wiel et al., 1981). This pattern of FSH release has also been observed in the rat (Chappel and Barraclough, 1976) and is considered by Van de Wiel (1981) to relate possibly to the low levels of oestradiol at this stage of the cycle; the data of Edwards (1980) shown in Figure 8.4 which indicate that in the pig this post-ovulatory rise in FSH secretion can be inhibited by oestradiol are consistent with this hypothesis. However, the presence of an ovarian 'inhibin' within porcine follicular fluid has also been extensively documented (Channing, 1979) and the removal of this source of inhibin at the time of ovulation has also been postulated to be the trigger for a rise in FSH in the immediate post-ovulatory period; in view of the specific feedback of inhibin on FSH secretion this would provide a more satisfactory explanation for the lack of an LH response at this time. Evidence for a pituitary site of action for inhibin from porcine follicular fluid has also been reviewed (Channing, 1979).

The biological significance of this post-ovulatory rise in FSH has been the subject of considerable speculation and at least in short-cycle species has been associated with the recruitment of the crop of follicles destined to ovulate at the subsequent oestrus (Schwartz, 1979). Whether this applies to long-cycle species such as the pig needs to be examined, although recent data from a small number of sows treated with oestradiol benzoate after weaning showed that even if these animals failed to conceive at the first post-treatment oestrus, they still returned to heat 21 days later. Thus, the 


\section{2}

Endocrine control of the oestrous cycle

presence of the post-ovulatory FSH rise is not an absolute requirement for subsequent follicular development. At the intra-ovarian level ovulation may also be associated with the removal of a non-steroidal luteinization inhibitor also shown to be present in porcine follicular fluid (Channing, 1979).

Following the immediate post-ovulatory period the rising levels of progesterone are associated with a stabilization of, and generally a slight decline in, FSH secretion (Vandalem et al., 1979; Edwards, 1980; Van de Wiel et al., 1981; see Figure 8.4). Over the same period there is the gradual development of episodic LH release of increasing amplitude and decreasing frequency, an effect that is considered to be a consequence of, rather than a stimulus for, the rising levels of peripheral progesterone (Foxcroft, 1978).

The rise in pre-ovulatory gonadotrophins has also been reported to be coincident with an increase in prolactin secretion by both Wilfinger (1974) and Van de Wiel et al. (1981). Although the role of prolactin at this time is uncertain the latter authors suggest a possible involvement in the endocrine trigger for the development of behavioural oestrus.

\section{Conclusions}

A consideration of even the limited amount of literature reviewed in this Chapter serves to illustrate the complexity of changes at all levels of the reproductive axis that may contribute to the endocrine control of the oestrous cycle. In many cases, however, critical experimental evidence is required to confirm what initially seem to be plausible functional interrelationships between the different hormones. Even if specific hormones are shown to be interdependent, the question still remains as to whether such changes are of direct consequence to the control of ovarian function.

An attempt to identify the possible critical regulators of cyclic ovarian function will, however, be made with particular reference to the recent data of Van de Wiel et al. (1979) and Van de Wiel and Pierantoni (personal communication), which describe the response of the pituitary to luteinizing hormone releasing hormone (LHRH) stimulation at different stages of the oestrous cycle (see Figure 8.5).

1. The dominant regulators of the pig oestrous cycle appear to be those factors that maintain the corpus luteum and in consequence block the final stages of follicular growth and steroidogenesis.

2. A requirement for luteotrophic support for the corpora lutea early in the oestrous cycle remains unresolved, but as a decline in luteal activity as early as day 10-12 of the cycle has been associated with changes in $\mathrm{LH}$ receptor levels, receptor inhibitory factors and increases in PGF production, LH support may be critical at this time.

3. No characteristic change in the pattern of $\mathrm{LH}$ secretion is obvious at the onset of luteal regression and LH secretion may be directly modulated by the feedback effects of progesterone, which only shows a latent decline on days 15-18 of the cycle. However both FSH basal levels and LHRH-induced LH and FSH responses are reported to decline before the fall in circulating progesterone (see Figure 8.5). This suggests that the pituitary may gradually become unresponsive as a result of the continuous secretion of progesterone during the luteal 

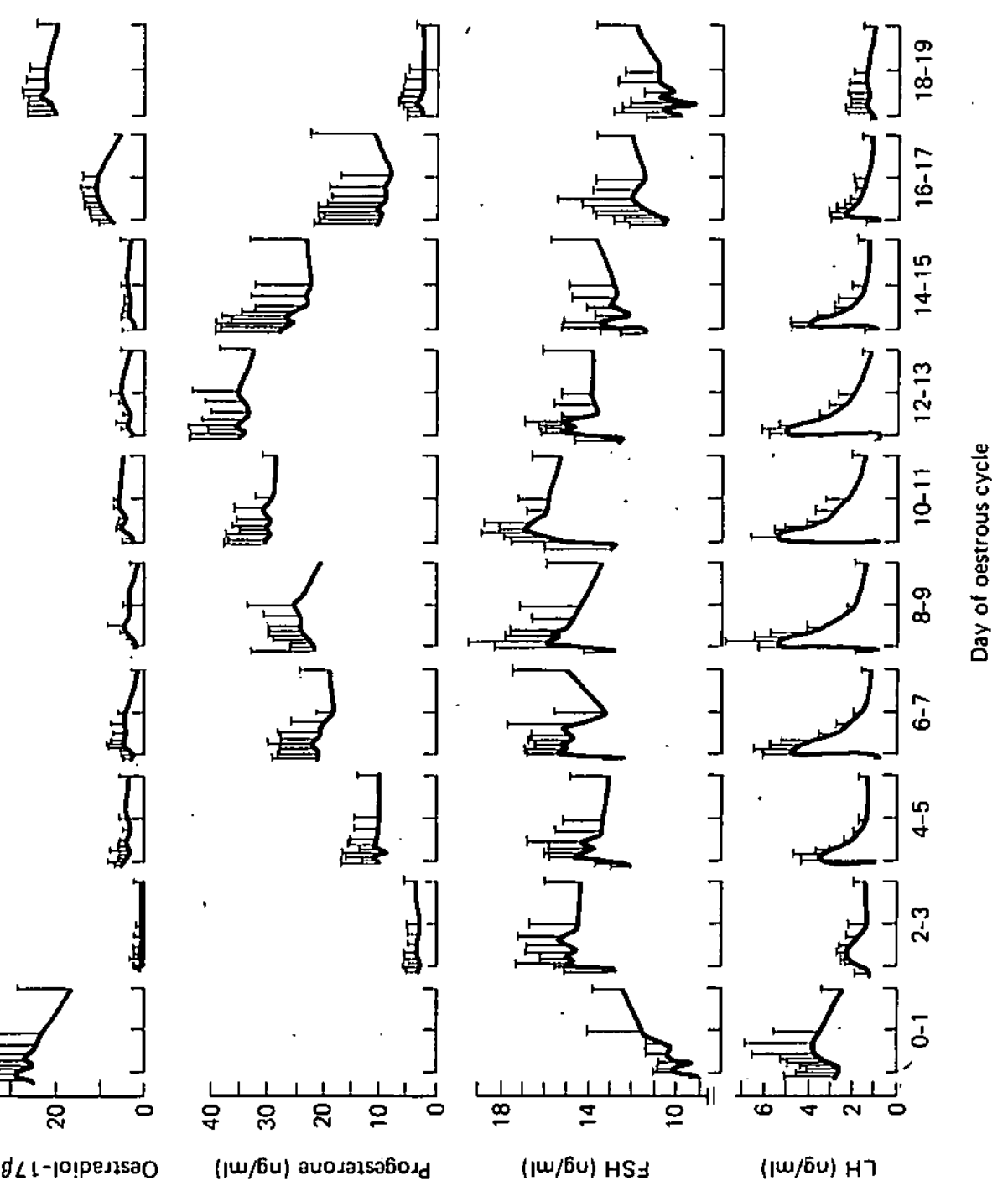

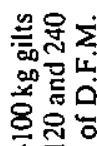

家

ㅇํㅁ 용 웅 울 공 동도 on 3 吾家 은

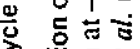
व. 5 总总 苾 웠 坖菏 氙 는 잉 을 을. 는 次 政

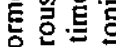
政 政 뭉

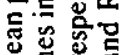
$\sum$. 嗐

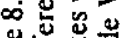
过

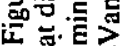


phase of the cycle (similar to the long-term effects of progesterone during pregnancy) or that another ovarian factor, possibly oestrogen, controls such changes at the hypothalamic-pituitary level. The trigger for luteal regression appears, however, to originate at the uteroovarian level with little evidence for the involvement of a critical change in the gonadotrophic stimulus received from the pituitary.

4. The block to continued follicular development and oestradiol secretion can be directly related to the presence of high progesterone levels in the circulation. The removal of this block could have effects at two levels of the reproductive axis. At the hypothalamic-pituitary level characteristic changes in the pattern of LH and FSH secretion occur, coincident with a period of enhanced prolactin release. It should be emphasized, however, that the nature of the change in gonadotrophin secretion involves a substantial decline in total secretion which may not appear to be consistent with the observation of an increase in gonadotrophin secretion as the usual trigger for gonadal development. Nevertheless the changes in LH/FSH release could result either in a particular pattern of episodic LH secretion and/or the achievement of a particular LH:FSH ratio that is of functional significance. Alternatively the withdrawal of progesterone at the ovarian level may remove an inhibition of one or more intra-ovarian factors which are known to be critical for the initiation of late follicular growth and steroidogenesis. Whatever the mechanisms involved, either one or both of these changes probably initially results in enhanced follicular secretion of oestradiol; this is then responsible for initiating a sequence of changes mainly regulated at the intra-ovarian level culminating in follicular growth, a rise in circulating oestrogen and oocyte maturation.

5. The oestrogen-induced surge of gonadotrophins usually involves both LH and FSH with a coincident rise in prolactin, followed in the immediate post-ovulatory period by an increase in FSH secretion alone. The LH surge directly induces intrafollicular changes leading to the luteinization of the granulosa cells and indirectly by causing ovulation, removes inhibitory effects at both the ovarian and pituitary level of a number of steroidal and non-steroidal regulators of follicular fluid origin. The biological significance of both the pre-ovulatory and post-ovulatory rises in FSH is uncertain.

6. During the follicular phase of the cycle the initial inhibition and subsequent enhancement of both LH and FSH responses to LHRH is consistent with the hypothesis that changes in pituitary sensitivity play a major role in the control of the surge secretion of gonadotrophins. Furthermore the marked suppression of LH and LHRH-induced LH responses during the initial inhibitory period of oestrogen feedback, and the overall characterisitcs of the LH surge, are in considerable contrast to the pattern of endocrine changes observed in other large domestic species and may be of physiological significance.

\section{References}

ANDERSON, L.D., SCHAERF, F.W. and CHANNING, C.P. (1979). Effects of follicular development on the ability of cultured porcine granulosa cells to convert androgens to estrogens. Adv. exp. Med. Biol. 112, 187-195 
ANDERSON, L.L. (1966). Pituitary-ovarian-uterine relationships. In Ovarian Regulatory Mechanisms. J. Reprod. Fert., Suppl. 1, 21-32

ARMSTRONG, D.T. and DORRINGTON, J.H. (1977). In Regulatory mechanisms affecting gonadal hormone action, Vol. 3, Advances in Sex Hormone Research, (J.A. Thomas and R.L. Singhal, Eds.), p. 217. Baltimore, University Press

CATT, K.J., HARWOOD, J.P., RICHERT, N.D., CONN, P.M., CONTI, M. and DUFAU, F. (1979). Luteal desensitization: hormonal regulation of LH receptors, adenylate cyclase and steroidogenic responses in the luteal cell. Adv. exp. Med. Biol. 112, 647-662

CHANNING, C.P. (1979). Follicular non-steroidal regulators. Adv. exp. Med. Biol. 112, 327-343

CHAPPEL, S.C. and BARRACLOUGH, C.A. (1976). Hypothalamic regulation of pituitary FSH secretion. Endocrinology 98, 927-935

COLENBRANDER, B. (1978). Aspects of sexual differentiation in the pig. PhD Thesis. State University of Utrecht

DU MESNIL DU BUISSON and LEGLISE, P.C. (1963). Effect de l'hypophysectomie sur les corps jaunes de la truis. Resultats préliminaires. C.r. hebd. Séanc. Acad. Sci., Paris 257, 261-263

EDQUIST, L.E. and LAMM, A.M. (1971). Progesterone levels in plasma during the oestrous cycle of the sow measured by a rapid competitive protein binding assay. J. Reprod. Fert. 25, 447-449

EDWARDS, S. (1980). Reproductive physiology of the postparturient sow. PhD Thesis. University of Nottingham

EILER, H. and NALBANDOV, A.V. (1977). Sex steroids in follicular fluid and blood plasma during the estrous cycle of pigs. Endocrinology 100, 331-338

ELSAESSER, F. and FOXCROFT, G.R. (1978). Maturational changes in the characteristics of oestrogen-induced surges of luteinizing hormone in immature gilts. J. Endocr. 78, 455-456

FOXCROFT, G.R. (1978). The development of pituitary gland function. In Control of Ovulation, (D.B. Crighton, G.R. Foxcroft, N.B. Haynes and G.E. Lamming, Eds.), p. 129. London, Butterworths

GOMES, W.R., HERSCHLER, R.C. and ERB, R.E. (1965). Progesterone levels in ovarian venous effluent of the non-pregnant sow. J. Anim. Sci. 24, 722-727

GREENWALD, G.S. (1979). Introductory remark; Ruminations on ovarian function. Adv. exp. Med. Biol. 112, 3-8

GUTHRIE, H.D., REXROAD, C.E. and BOLT, D.J. (1979). In vitro release of progesterone and prostaglandins $\mathrm{F}$ and $\mathrm{E}$ by porcine luteal and endometrial tissue during induced luteolysis. Adv. exp. Med. Biol. 112, 627-632

HANSEL, W., CONCANNON, P.W. and LUKASZEWSKA, J.H. (1973). Corpora lutea of the large domestic animals. Biol. Reprod. 8, 222-245

HENRICKS, D.M., GUTHRIE, H.D. and HANDLIN, D.L. (1972). Plasma oestrogen, progesterone and $\mathrm{LH}$ levels during the oestrous cycle in pigs.

Biol. Reprod. 6, 210-218

HUNZICKER-DUNN, M., BOCKAERT, J. and BIRNBAUMER, L. (1978). In Receptors and Hormone Action, Vol. 3, (B.W. O'Malley and L. Birnbaumer, Eds.), p. 393. New York, Academic Press

HUNZICKER-DUNN, M., JUNGMANN, R., DERDA, D. and BIRNBAUMER, L. 
(1979). LH-induced desensitization of the adenylyl cyclase system in ovarian follicles. Adv. exp. Med. Biol. 112, 27-44

KOTWICA, J. (1980). Mechanism of prostaglandin $F_{2 \alpha}$ penetration from the horn of the uterus to the ovaries in pigs. J. Reprod. Fert. 59, 237-241

LEUNG, P.C.K., TSANG, B.K. and ARMSTRONG, D.T. (1979). Estrogen inhibits porcine thecal androgen production in vitro. Adv. exp. Med. Biol. 112, 241-243

LIPTRAP, R.M. and RAESIDE, J.I. (1966). LH activity in blood and urinary oestrogen excretion by the sow at oestrus and ovulation. J. Reprod. Fert. 11, 439-446

LUNAAS, T. (1962). Urinary oestrogen levels in the sow during oestrous cycle and early pregnancy. J. Reprod. Fert. 4, 13-20

MASUDA, H., ANDERSON, L.L., HENRICKS, D.M. and MELAMPY, R.M. (1967). Progesterone in ovarian venous plasma and corpora lutea of the pig. Endocrinology 80, 240-246

NALBANDOV, A.V. (1970). Comparative aspects of corpus luteum function. Biol. Reprod. 2, 7-13

NISWENDER, G.D., REICHERT, L.E. and ZIMMERMAN, D.R. (1970). Radioimmunoassay of serum levels of luteinizing hormone throughout the estrous cycle in pigs. Endocrinology 87, 576-580

PARVIZI, N., ELSAESSER, F., SMIDT, D. and ELLENDORFF, F. (1976). Plasma luteinizing hormone and progesterone in the adult female pig during the oestrous cycle, late pregnancy and lactation, and after ovariectomy and pentobarbitone treatment. J. Endocr. 69, 193-203

PEROTTI, L., ENNE, G., MEGGIOLARO, D. and DELRIO, G. (1979). Concentrazione plasmatica de progesterone in scrofe durante cicli estrali estivi ed invernali. Revta Zootech. Vet. 1, 10-12

RAESIDE, J.I. (1963). Urinary oestrogen excretion in the pig at oestrus and during the oestrous cycle. J. Reprod. Fert. 6, 421-426

RAYFORD, P.L., BRINKLEY, H.J. and YOUNG, E.P. (1971). Radioimmunoassay determination of LH concentration in the serum of female pigs. Endocrinology 88, 707-713

RAYFORD, P.L., BRINKLEY, H.J., YOUNG, E.P. and REICHERT, L.E. (1974). Radioimmunoassay of porcine FSH. J. Anim. Sci. 39, 348-354

RICHARDS, J.S., RAO, M.C. and IRELAND, J.J. (1978). In Control of Ovulation, (D.B. Crighton, G.R. Foxcrott, N.B. Haynes and G.E. Lamming, Eds.), pp. 197-216. London, Butterworths

ROLLAND, R., GUNSALUS, G.L. and HAMMOND, J.M. (1976). Demonstration of specific binding of prolactin by porcine corpora lutea. Endocrinology 98, 1083-1091

SCHWARTZ, N.B. (1979). In discussion. Adv. exp. Med. Biol. 112, 399-400

SCHWARTZ-KRIPNER, A. and CHANNING, C.P. (1979). Changes in responsiveness of porcine granulosa cells to prostaglandins and luteinizing hormone in terms of cyclic-AMP accumulation during follicular maturation. Adv. exp. Med. Biol. 112, 137-143

SHEARER, I.J., PURVIS, K., JENKIN, G. and HAYNES, N.B. (1972). Peripheral plasma progesterone and oestradiol-17 $\beta$ before and after puberty in gilts. J. Reprod. Fert. 30, 347-360

SPIES, H.G., SLYTER, A.L. and QUADRI, S.K. (1967). Regression of corpora lutea in pregnant gilts administered antiovine LH rabbit serum. J. Anim. Sci. 26, 768-771 
STABENFELDT, G.H. AKINS, E.L., EWING, L.L. and MORRISSETTE, M.C. (1969). Peripheral plasma progesterone levels in pigs during the oestrous cycle. J. Reprod. Fert. 20, 443-449

TILLSON, S.A. and ERB, R.E. (1967). Progesterone concentration in peripheral blood plasma of the domestic sow prior to and during early pregnancy. J. Anim. Sci. 26, 1366-1368

TILLSON, S.A., ERB, R.E. and NISWENDER, G.D. (1970). Comparison of LH and progesterone in urine of domestic sows during the oestrous cycle and early pregnancy. J. Anim. Sci. 30, 795-805

TUCKER, S., KUMARI, L., and CHANNING, C.P. (1979). Evidence of a greater activity of $\mathrm{LH} / \mathrm{HCG}$ binding inhibitor present in aqueous extracts from old compared to young porcine corpus luteum. Adv. exp. Med. Biol. 112, 723-728

VANDALEM, J.L., BODART, Ch., PIRENS, G., CLOSSET, J. and HENNEN, G. (1979). Development and application of homologous radiommunoassays for porcine gonadotrophins. J. Endocr. 81, 1-10

VAN DE WIEL, D.F.M., BAR-AMI, S., TSAFRIRI, A. and DE JONG, F.H. (1982). Oocyte maturation inhibitor, inhibin and steroid concentrations in porcine follicular fluid of various stages of the oestrous cycle. Submitted for publication

VAN DE WIEL, D.F.M., VAN DE BOEZEM, E.A., VERGROESEN, L.P.B.M. and DE VRIES, F.P.W. (1979). Feedback action of progesterone and oestrogen on LH responses after administration of $\mathrm{GnRH}$ in cycling gilts. In Research on Steroids, Vol. VIII, (A. Klopper, L. Lerner, H.J. Van der Molen and F. Sciarra, Eds.), pp. 221-224. London, Academic Press

VAN DE WIEL, D.F.M., ERKENS, J., KOOPS, W., VOS, E. and VAN LANDEGHEM, A.A.J. (1981). Perioestrous and midluteal time courses of circulating LH, FSH, prolactin, estradiol-17 $\beta$ and progesterone in the domestic pig. Biol. Reprod. 24, 223-233

VAN LANDEGHEM, A.A.J. and VAN DE WIEL, D.F.M. (1977). Plasma prolactin levels in gilts during the oestrous cycle and at hourly intervals around the time of oestrus. Acta endocr., Copenh., Suppl. 212, 143

WATSON, J. and LEASK, J.T.S. (1975). Superfusion in vitro in the study of ovarian steroidogenesis. J. Endocr. 64, 163-173

WEISS, J.R., BRINKLEY, H.J. and YOUNG, E.P. (1976). In vitro steroidogenesis in porcine corpora lutea. J. Anim. Sci. 42, 121-130

WILFINGER, W.W. (1974). Plasma concentrations of luteinizing hormone, follicle stimulating hormone and prolactin in ovariectomized, hysterectomized and intact syjine. PhD Thesis. University of Maryland

ZIECIK, A., SHAW, H.J. and FLINT, A.P.F. (1980). Luteal LH receptors during the oestrous cycle and early pregnancy in the pig. J. Reprod. Fert. 60, $129-137$ 